\title{
Assessment of Adolescent Risk Behaviours in Junior High Schools in the Cape Coast Metropolis of Ghana
}

\author{
Jones Clifford Akosah $^{1^{*}} \quad$ Bernard Yaw Sekyi Acquah $^{2} \quad$ Serwaa Adu-Gyamfi ${ }^{1}$ \\ 1.Department of Guidance and Counselling, University of Cape Coast, Cape Coast, Ghana \\ 2.Department of Business and Social Sciences Education, University of Cape Coast, Cape Coast, Ghana
}

\begin{abstract}
The study investigated adolescent risk behaviours in public junior high schools of the OLA circuit in the Cape Coast Metropolis using the descriptive survey design. Five research questions and two hypotheses were formulated to guide the study. The target population of the study was all students in the OLA Circuit of the Cape Coast Metropolis. The accessible population was all students from the three selected schools in the OLA Circuit. The Multi-stage sampling procedure was used to select 155 students for the study. Proportional stratified sampling and simple random sampling techniques were employed. The data were analysed using means, standard deviations and independent samples t-test. The study revealed that students' engagement in any of the adolescents risk behaviours thus violence-related behaviour, alcoholism, smoking, risky sexual behaviours and suicidal tendencies were very minimal. There was a significant difference between male and female risky sexual behaviours. However, there was no significant difference between male and female on the basis of suicidal tendencies. Based on these findings, it was recommended that the Ministries of Health, Education, Youth and Sports, National population Council (NPC), among others continue to intensify their campaigns against adolescents risk behaviours.
\end{abstract}

Keywords: assessment, adolescence; adolescent; risk behaviours; junior high school students

DOI: $10.7176 / \mathrm{JEP} / 10-25-05$

Publication date:September $30^{\text {th }} 2019$

\section{Introduction}

Adolescence is a stage in which there are many changes in the individual such as biological, cognitive and sociocultural changes. At this stage of life, many individuals are very vulnerable and the kind of behaviour an individual chooses goes a long way to either negatively or positively impact on the person's future. Information from the Ghana Statistics Service (2008) on the Ghana Demographic and Health Survey indicated that adolescents (10-19 years) constitute nearly $22 \%$ of the population of Ghana, with young people (10-24 years) accounting for about one third.

Colin (2013) defined adolescence as "the period of time in a person's life when they are developing into an adult" (p.21). The $21^{\text {st }}$ century adolescent is faced with a lot of risk behaviours that have the potency for immediate and severe consequences. The transitional stage from childhood to adulthood is usually considered between 13 to 19 years. Nonetheless, the physical and psychological changes that occur in adolescents can start earlier from age 9 to 12 years. Adolescence may be a time of disorientation and discovery. This is a time of growth and discovery where young people encounter confusion and anxieties in what is right or wrong and safe or dangerous. Sexuality is at its peak during this transition period.

Adolescents are generally perceived to be healthy (Richter, 2010). However, adolescent risk behaviours such as substance use, suicides, violence and early sexual activity are matters that keep making media headlines. Globally, the past decades have witnessed a remarkable increase in the theoretical and empirical research being done on risk behaviours among young people (Richter, 2010). According to Jessor (1998), in spite of considerable explanatory efforts, research on risk behaviour in adolescence is still facing two complementary challenges. They are:

1) understanding the processes that link risk behaviour to outcomes that compromise well-being, health and the life course (consequences of risk behaviour).

2) understanding why an adolescent engages in risk behaviour in the first place and identifying the proximate and distal experiences that influence engagement in risk behaviour (determinants of risk behaviour).

Even though risk behaviours are not limited to one period of life, adolescence has a special importance due to the fact that risk behaviours are to a large extent established in this period. Generally, the concept of 'risk behaviour' is mostly recognised as a specific form of inappropriate handling of problems during this time (Hurrelmann \& Richter, 2006). Risk behaviour is understood to be behaviour with undesirable consequences that goes hand in hand with a probability of harm or loss. Although there is no clear consensus in the literature about the definition of or the key elements encompassed in the concept of risk behaviour, it is generally agreed that such behaviours are those that are directly or indirectly associated with health and well-being (Hurrelmann \& Richter, 2006).

Research work by Jessor (1998) has extended the perimeter around these problem behaviours and has recognised the functional commonality of risk behaviours with other areas of adolescent activity. Such areas 
compromise healthy development such as inadequate social role performance (such as poor school progress), psychopathology (such as depression), and health compromising behaviours (such as poor dietary practices or insufficient exercise). The term "risk behaviour", therefore, refers to any behaviour that can compromise psychosocial aspects of successful adolescent development. Substance use, delinquency, unhealthy dietary behaviour, reckless driving as well as inadequate psychosocial adjustment are some obvious examples (Kulbok \& Cox, 2002; Hurrelmann \& Richter, 2006). However, psychological impairments such as depression, bulimia and anorexia nervosa can also be seen as risk behaviours. Thus, risk behaviours can be considered as risk factors for personally, socially or developmentally undesirable outcomes. These adverse outcomes can have enduring consequences at considerable cost to individuals, families and the wider community.

Young people constitute a major potential for socio-economic development in every country. In Ghana, young people aged 15-24 years account for about 30 per cent of the total population (National Population Council, 2000). Adolescent involvement in risk behaviour is a major threat to national development, family stability and social security. Some possible problems that risk behaviours create include rape, bullying, stealing, assault, damage to school properties and even death. The overall development of the nation is hampered if students become liability as a result of this phenomenon. Various programmes both official and unofficial have been organized to address the menace in Ghana. The Ghana Education Service has for some years been conducting drug abuse education in schools on ad-hoc basis to increase awareness and to monitor its benefits through its Curriculum Research and Development Division. In addition, out of school youth are often educated through mass media and public lectures organised by non-governmental organisations on dangers associated with some of these adolescence risk behaviours. Others have also tried to draw the attention of policy makers to this elusive means of adolescents' destruction. For instance, in the February 13-19th edition of the Junior Graphic (a popular weekly youth magazine) in 2003 as cited in Nkyi (2014), an NGO called Ghana Coalition on the Rights of the child called on the Minister of Justice to come up with a protection code against smoking for children in the country.

However, the available literature in the Ghanaian setting are studies that singled out an aspect of adolescent risk behaviours such as drug abuse, sexual behaviours, alcohol use among others. For instance, the studies of AduMireku (2003) and Amonoo-Lartson and Pappoe (1992) focused on the prevalence of smoking, alcohol, cigarette, and marijuana use among senior secondary school students. Again, the works of Boamah (2012) and Agyei (2000) both concentrated on sexual behaviours and contraception among senior high students. Research done by Nkyi (2014), Doku (2012) and Lamptey (2005) also only explored substance use in senior high schools. To add, Kokutse (2012), the World Health Organisation (2012), Osafo, Hjelmeland, Akotia and Knizek (2011) and Adinkrah (2010) narrowed their studies to look into suicide in Ghana. Furthermore, Nyarko (2015) and Acquah, Wilson and Doku (2014) also focused their studies on the prevalence of bullying among students. All the studies above have looked at adolescents risk behaviours in single way not combining any two or more of the identified behaviours to get a more holistic perspective as this present study sought to achieve. This is coupled with another case where most of these studies have concentrated on senior high school students (Adu-Mireku, 2003; Boamah, 2012; Doku, 2012) neglecting the junior high school students who are much more vulnerable.

It is against this background that this study was conducted to assess adolescent risk behaviours in public junior high schools of the OLA circuit in the Cape Coast Metropolis.

\section{Purpose of the Study}

The study intended to find out:

1. adolescents engagement in violent-related behaviours,

2. adolescents involvement in alcoholism,

3. adolescents engagement in smoking,

4. adolescents involvement in risky sexual behaviours and

5. adolescents engagement in suicidal tendencies.

\section{Research Questions}

The research questions to guide the study were as follows.

1. What violence-related behaviours do adolescents engage in?

2. What alcohol-related behaviours do adolescents involve themselves?

3. What smoking behaviours do adolescents engage in?

4. What sexual behaviours do adolescents involve themselves?

5. How frequent do adolescents have suicidal tendencies?

\section{Hypotheses}

The following hypotheses were tested.

1. $\mathrm{H}_{0}$ : There is no significant difference in sexual behaviours of adolescents on the basis of gender. $\mathrm{H}_{1}$ : There is significant difference in sexual behaviours of adolescents on the basis of gender. 
2. $\mathrm{H}_{0}$ : There is no significant difference in suicidal tendencies of adolescents on the basis of gender. $\mathrm{H}_{1}$ : There is significant difference in suicidal tendencies of adolescents on the basis of gender.

\section{Methodology}

\subsection{Research Design}

The descriptive survey method was used. This was because the current study sought to describe the prevailing status of adolescent risk behaviours in the OLA Circuit of the Cape Coast Metropolis. Fraenkel and Wallen (2002) stated that descriptive survey present facts or current situations concerning the nature of a group of persons, a number of objects or a class of events and may include the procedure of induction, analysis, classification, enumeration or measurement.

However, the descriptive survey design has some disadvantages. Fraenkel and Wallen (2002) have stated that with private and emotional matters, respondents may not be completely truthful to delve into making the results superficial and not credible. Nevertheless, the descriptive survey design was found to be most appropriate and applicable for this study considering the fact that the researchers were interested in knowing and describing the prevalence of adolescent risk behaviours in public junior high schools of the OLA circuit in the Cape Coast Metropolis.

\subsection{Population}

The target population of this study comprised students in the public junior high schools in the OLA circuit of the Cape Coast Metropolis with a total number of 671. The accessible population was three schools in the OLA circuit with a total number of students of 258. This figure is made up of 121 males and 137 females for the 2016/2017 academic year (Ghana Education Service, Cape Coast Metropolis, 2016).

\subsection{Sampling Procedure}

Out of the students' population of 258, a sample size of 155 students made up 73 males and 82 females participated in the study. Krejcie and Morgan's (1970) table for sample size estimation was used to determine the sample size. Sampling techniques that were used are the proportional stratified and simple random sampling. In the first stage, proportionate number of respondents based on gender and academic form in each junior high school was determined. In the second stage, the simple random sampling technique was used to select the subjects from the two classes (form 1 and 2) using the lottery method. This is because form three students were not available as at the time of data collection.

\subsection{Data Collection Instrument}

A questionnaire was used to gather data for the study. The instrument consists of two sections. Section A involves respondents' background information such as such as age, gender, form and religion. Section B contains 5 scales of 29 items. The scales are Violence-Related Behaviour, Alcohol Use, Smoking, Sexual Behaviour and Suicidal Tendencies. The scales are all measured on a four-point Likert-type scale format. The response options are: $4=$ Very Often, $3=$ Often, $2=$ Not Often and $1=$ Not at all. According to Amedahe (2002), Likert-type scale questionnaires have high return rate and are more advantageous than open-ended questionnaires. A high mean score on a scale implies that there is an engagement in a particular risk behaviour.

The content validity of the instrument was carried out by some experts of the Department of Guidance and Counselling and the Department of Psychology and Education in the University of Cape Coast. To improve the validity and the reliability of the instrument, pre-testing was done in the University Junior High School in the Cape Coast Metropolis. The Cronbach's coefficient alpha gave a reliability of 0.84 after the pre-testing. There was hundred per cent return rate of the questionnaires. Ethical principles such as informed consent and confidentiality of responses were strictly adhered to. In order to ensure informed consent, it was explained to the students that participation was completely voluntary and participants were also assured of their freedom to withdraw from the study at any time if they wished to do so on the designated survey day.

\subsection{Data Processing and Analysis}

Both descriptive and inferential statistical tools were used in the analysis of the data. Frequency and percentages were used to analyse the demographic data. Mean scores and standard deviations were used to analyse the responses to the five research questions. The independent-samples t-test was used to test the hypotheses. An alpha level of .05 was used for all statistical tests.

\section{Results}

The results are presented as follows:

Research question 1: What violence-related behaviours do adolescents engage in?

This research question sought to find out the violence-related behaviours adolescents engage in. The results are 
presented in Table 1.

Table 1-Adolescents Engagement in Violence-related Behaviour $(N=155)$

\begin{tabular}{lll}
\hline Statement & Mean & SD \\
\hline Carry a weapon & 1.08 & 0.34 \\
Threaten people with weapons & 1.00 & 0.08 \\
Engage in group physical fights & 1.14 & 0.43 \\
Engage in one on one physical fight & 1.24 & 0.61 \\
Walk away from a fight I feel like a coward & 1.37 & 0.79 \\
\hline Average scores & 1.17 & 0.45 \\
\hline
\end{tabular}

From Table 1, an examination of the individual items shows that students did not feel like cowards at all when they walked away from a fight $(\mathrm{M}=1.37, \mathrm{SD}=0.79)$. It was also revealed that adolescents did not all engage in one-on-one fight $(\mathrm{M}=1.24, \mathrm{SD}=0.61)$ or group physical fights $(\mathrm{M}=1.114, \mathrm{SD}=0.43)$.

Research question 2: What alcohol-related behaviours do adolescent involve themselves?

This research question sought to find out the alcohol-related behaviours of adolescent. The result is presented in Table 2.

Table 2-Adolescents Engagement in Alcoholism $(N=155)$

\begin{tabular}{lll}
\hline Statement & Mean & SD \\
\hline Try drinking alcohol & 1.08 & 0.33 \\
Get drunk to the extent that people carry me home & 1.02 & 0.14 \\
Enjoy drinking all forms of alcohol & 1.01 & 0.11 \\
Drink alcohol when I am alone & 1.03 & 0.27 \\
Drink alcohol when I am in a group & 1.01 & 0.08 \\
\hline Average scores & 1.03 & 0.19 \\
\hline
\end{tabular}

From Table 2, it was observed that students did not drink when they are in a group $(\mathrm{M}=1.01, \mathrm{SD}=0.08)$ or alone $(\mathrm{M}=1.03, \mathrm{SD}=0.27)$. Table 3, further revealed that students did not try drinking alcohol $(\mathrm{M}=1.08, \mathrm{SD}=0.33)$.

Research Question 3: What smoking behaviours do adolescents engage in?

The purpose of this research question was to find out the smoking behaviours of adolescent. The result is presented in Table 3.

Table 3-Adolescents Engagement in Smoking ( $N=155)$

\begin{tabular}{lll}
\hline Statement & Mean & SD \\
\hline Tried smoking marijuana or tobacco products & 1.05 & 0.31 \\
Smoke marijuana or tobacco products when with a group & 1.01 & 0.08 \\
Tend to sit in the midst of people who smoke & 1.05 & 0.24 \\
Smoke marijuana or tobacco products when I am alone & 1.03 & 0.25 \\
Enjoy smoking marijuana or tobacco products & 1.03 & 0.27 \\
\hline Average scores & 1.03 & 0.23 \\
\hline
\end{tabular}

It can be noted from Table 4 that adolescents did not at all tried smoking marijuana or tobacco products $(\mathrm{M}=1.05, \mathrm{SD}=0.31)$ and neither did they sit in the midst of people who smoke $(\mathrm{M}=1.05, \mathrm{SD}=0.24)$. It can also be seen that adolescents did not smoke marijuana or tobacco products when alone $(\mathrm{M}=1.03, \mathrm{SD}=0.27)$.

Research Question 4: What sexual behaviours do adolescents involve themselves?

This research question sought to find out the sexual behaviours of adolescent. The result is presented in Table 4 .

Table 4-Adolescents Engagement in Risky Sexual Behaviours (N=155)

\begin{tabular}{lll}
\hline Statement & Mean & SD \\
\hline Engage in sexual activities & 1.21 & 1.02 \\
Change my sexual partners & 1.13 & 0.53 \\
Drink alcohol or use drugs before I have sexual intercourse & 1.07 & 0.39 \\
Enjoy sex without condom & 1.14 & 0.91 \\
Practice oral sex with my partner & 1.08 & 0.43 \\
Have been forced by somebody to engage in sexual activities & 1.17 & 0.58 \\
Force people to engage in sexual activities & 1.04 & 0.28 \\
Physically hurt people I am dating or going out with on purpose & 1.06 & 0.33 \\
\hline Average scores & 1.11 & 0.56 \\
\hline
\end{tabular}

It can be seen from Table 4 that adolescents did not at all engaged in sexual activities $(\mathrm{M}=1.21, \mathrm{SD}=1.02)$ neither have they been forced by somebody to engage in sexual activities $(\mathrm{M}=1.17, \mathrm{SD}=0.58)$. Again, adolescents stated that they did not forced people to engage in sexual activities at all $(\mathrm{M}=1.04, \mathrm{SD}=0.28)$. Similarly, adolescents did not practice oral sex at all $(\mathrm{M}=1.08, \mathrm{SD}=0.91)$.

1. Research Question 5: How frequent do adolescents have suicidal tendencies?

This research question sought to find out the rate of suicidal tendencies of adolescents. The result is presented in 
Table 5.

Table 5-Adolescents Engagement in Suicidal Tendencies ( $N=155)$

\begin{tabular}{lcc}
\hline Statement & Mean & SD \\
\hline Feel so sad every day & 1.57 & 0.70 \\
Feel hopeless that it makes me stop doing some usual activities & 1.45 & 0.77 \\
Think of attempting suicide & 1.37 & 1.15 \\
Plan to commit suicide & 1.27 & 1.00 \\
Attempt suicide & 1.16 & 0.56 \\
Attempted suicide that resulted in an injury, poisoning, or overdose & 1.08 & 0.46 \\
\hline Average scores & 1.32 & 0.77 \\
\hline
\end{tabular}

From the Table 5 , it can be noted that the adolescents did not often feel sad everyday $(\mathrm{M}=1.57, \mathrm{SD}=0.70)$. Table 6, also revealed that adolescents did not often feel hopeless that made them stopped doing some usual activities $(\mathrm{M}=1.45, \mathrm{SD}=0.77)$. Again, adolescents did not attempt suicide that resulted in an injury, poisoning or overdose $(\mathrm{M}=1.08, \mathrm{SD}=0.46)$.

Hypothesis 1: There is no significant difference in the sexual behaviours of students on the basis of gender.

To determine whether significant difference exists in the sexual behaviours of students on the basis of gender, independent samples t-test was conducted. The results are presented in Table 6.

Table 6- Independent Samples t-test on Male and Female Students Regarding their Risky Sexual Behaviours

\begin{tabular}{|c|c|c|c|c|c|c|}
\hline Gender & $\mathrm{N}$ & Mean & SD & $\mathrm{df}$ & t-cal & Sig (2tailed) \\
\hline Male & 74 & 9.51 & 4.04 & & & \\
\hline Female & 81 & 8.30 & 1.30 & 86.776 & $2.453^{*}$ & .016 \\
\hline
\end{tabular}

*Significant, $\mathrm{p}<0.05$

Table 6 shows the independent samples t-test performed on male and female students regarding their risky sexual behaviours. The significance level of Levene's test which was 0.00 was lesser than 0.05 implying that the variances for the two groups (males/females) were not the same. Therefore, the assumption of equal variance was violated. It was revealed that the male had a mean score of 9.51 and a standard deviation of 4.04 whereas the female had a mean score of 8.30 and a standard deviation of 1.30. It can, therefore, be concluded that there was a significant difference in adolescents risky sexual behaviours on the basis of gender $(t=2.453, d f=86.776, p=0.016$, 2 -tailed). Males were more likely to have risky sexual behaviours than females. The probability value ( $p$-value) of 0.016 is less than the 0.05 significant level. Therefore, based on the result above the null hypothesis is rejected.

Hypothesis 2: There is no significant difference in suicidal tendencies of students on the basis of gender. To determine whether significant difference exists in the suicidal tendencies of students on the basis of gender, independent samples t-test was conducted. The results are presented in Table 7.

Table 7-Independent Samples t-test on Male and Female Students on the Basis of Suicidal Tendencies

\begin{tabular}{lcccccc}
\hline Gender & $\mathrm{N}$ & Mean & SD & Df & t-cal & Sig (2tailed) \\
\hline Male & 74 & 8.12 & 3.29 & & & \\
& & & & & & \\
Female & 81 & 7.07 & 3.09 & & .816 & .416 \\
\hline
\end{tabular}

Table 7 shows the independent samples t-test performed on male and female students regarding their suicidal tendencies. The significance level of Levene's test which was 0.98 was greater than 0.05 implying that the variances for the two groups (males/females) were the same. Therefore, the assumption of equal variances was assumed. It was revealed that the male had a mean score of 8.12 and a standard deviation of 3.29 whereas the female had a mean score of 7.07 and a standard deviation of 13.09. It can, therefore, be concluded that there was no significant difference in suicidal tendencies of adolescents on the basis of gender $(t=.816, d f=153, p=.416,2$ tailed). The probability value ( $\mathrm{p}$-value) of .416 is greater than the 0.05 significant level. Therefore, based on the result above, the null hypothesis is retained.

\section{Discussion of findings}

This section discussed the various findings of the study in relation to the research questions and hypotheses using relevant literature.

\section{Adolescents Engagement in Violence-related Behaviour}

With respect to the research question one on the violence-related behaviours adolescents engage in, it was observed that the adolescents stated they did not engage in violence-related behaviours. This finding is in sharp contrast to 
a number of studies. It contradicts the findings of Acquah, Wilson and Doku (2014), which revealed that there were high levels of violent-related behaviours such as bullying among Ghanaian adolescents. Again, the current finding is inconsistent with the study of Nyarko (2015) on the sociological assessment of the causes and consequences of youth violence in the Kumasi Metropolis. The study concluded that there was high prevalence of violence and the principal categories of violence were manifested in noise making, rape, murder, stealing and drug addiction, obscene gestures, robbery, stealing, bullying, hitting, fighting, swearing, threatening, shoving/pushing, yelling, sexual abuse and embarrassing.

However, it can be seen from the current study that items such as 'I carry a weapon such as a knife, or club around'; 'I threaten people with weapons such as a knife, or club' did not at all find their way in the lives of the adolescents. This finding may be accounted for by the fact that adolescents used for the study were very young and, therefore, may be deemed very fragile to engage in any violence-related behaviours.

\section{Adolescents Engagement in Alcoholism}

With respect to the second research question on the alcohol-related behaviours of adolescents, it was revealed that they did not engage in alcoholism. This finding is inconsistent with a study by Fatoye (2003), among secondary schools students in south western Nigeria in which $13 \%$ of students reported high alcohol use while $26 \%$ had ever consumed alcohol. The current finding also contradicts a study by Peltzer (2009) on substance use among schoolgoing adolescents in six African countries. It indicated that $6.6 \%$ of students surveyed engaged in risky alcohol use (two or more per day for at least 20 days or more in the past month).

The possible reason for this current finding may be due to the fact that there is an increase in the number of alcoholism free advocacy groups who move from schools to schools to speak to students about alcohol and its effects. Again, it may be said that due to the age level of the respondents from the demographic data, they might have not reached the curiosity stage where there is the tendency for them to try and take alcohol.

\section{Adolescents Engagement in Smoking}

The third research question sought to ascertain the smoking behaviours adolescents engage in. It was observed that adolescents did not engage in smoking. This finding agrees with the study of Fawibe and Shittu (2011) who stated that although smoking was found to prevail among non-medical students, its prevalence was low 5.7\% (males $7.7 \%$, females $2.0 \%$ ). The current finding does not agree with the study of Al-Yousaf and Karim (2001) on the prevalence of smoking among high school students which concluded that the rate of smoking is high among adolescent students in Alkharj. The study also revealed that the average starting age for current smokers was 13.8 years (13 years-15 years) and $105(63 \%)$ of current smokers smoked less than 10 cigarettes per day (light smokers). Again, the influence of friends $96(58 \%)$ and the presence of smoking in the family $53(32 \%)$ were the two most important factors influencing the rate of smoking in current smokers.

In addition, the current finding is inconsistent with the study investigated by Emeke and Adegoke (2005) on the prevalence of smoking among the adolescents in Ibadan South-East. It was observed that of the 500 adolescents sampled, the rate of smoking was very high among the males than females. Peltzer (2009) also conducted a study on substance use among school-going adolescents in six African countries in which it was concluded $10.5 \%$ of the respondents engaged in smoking (three or more times ever).

One of the possible reasons that could account for the low engagement in smoking among adolescents in this study is the fact that parental care may be very strong especially for students at the level of education. Effective parental care has been seen to be potent enough to savage children who are going wayward. Again, it is possible that school rules and regulations may be restricting students from engaging in smoking. Adolescents at this level may not have the courage to flout school rules and regulations and do their own things. Another reason could be that adolescents are restricted in terms of their movement either by parents and guardians; therefore, they do not have the total freedom for themselves. This is because the Ghanaian community sees them to be weak and fragile people who must be assisted in all their endeavours.

\section{Adolescents Engagement in Risky Sexual Behaviours}

With respect to the fourth research question which addressed the engagement of adolescents in risky sexual behaviours, it was seen that adolescents did not engaged in risky sexual behaviours. This is inconsistent with a number of studies. In a study conducted by Awusabo-Asare and Biddlecom (2006) among Ghanaian adolescents, it was discovered that, $30 \%$ and $16 \%$ of the females and males aged 15 to 19 respectively have had sex with a majority of it being premarital. Again, according to the report of the Ghana National Demographic and Health Survey in 2008, of the 15 to 19 year olds interviewed, among those who have had sex, $73.6 \%$ of the females and $96.2 \%$ of the males had sexual intercourse with someone who was neither their spouse nor a co-habiting partner and $19.4 \%$ of them were in concurrent relationships.

One of the possible reasons for the current finding could be that adolescents did not really want to disclose their sexual lifestyle since such things are usually considered to be private. Another possible reason could be that 
adolescents used in this study do not have the pleasure to engage in sexual intercourse given their age level and forms. It is also possible that the introduction of sexual education at the basic school level is having a great positive impact on the lives of the adolescents. Again, another factor could be that teenage pregnancy campaign especially in the Cape Coast Metropolis has been fruitful in teaching adolescents to make use of contraceptives or if possible to abstain from sex until marriage. It is also possible that since the respondents were students they did not have to battle with streetism and its accompanying challenges as other adolescents.

Hypothesis one was formulated to find out if there was a significant difference in risky sexual behaviours of adolescents on the basis of gender. The current study revealed that there was a significant difference in risky sexual behaviours of adolescents on the basis of gender. This is to say that males were more likely to have risky sexual behaviours than females. This agrees with a study by Karim, Magnani, Morgan and Bond (2003), which indicated that $18 \%$ and $27 \%$ of adolescent males and females who have had sexual intercourse mentioned that they used condoms in their maiden sexual encounter. It also agrees with another study by Boamah (2012) in which it was stated that adolescents who have been in a relationship have also engaged in concurrent relationships thus, being in a relationship with more than one partner at the same time. It was revealed that $6 \%$ of females and $15 \%$ of males agreed to this.

One reason that may account for this current finding could be that males are dominant in terms of their sexual relationships and, therefore, may choose the kind of sexual behaviour that suites them with or without the consent of their partners. Again, males may have the perception that sex cannot be detached from their relationships. It is also possible that the females do not want to give details of their sexual lives since the Ghanaian culture does not permit them to do so as compared to their male counterparts.

\section{Frequency of Adolescents in Engaging Suicidal Behaviours}

Research question five explored adolescents' tendencies to engage in suicide. It was revealed that adolescents did not have suicidal tendencies. This finding is in sharp contrast with the finding of Asante, Kugbey, Osafo, Quarshie, Sarfo (2017) in which it was revealed that the prevalence of suicidal behaviours was high $18.2 \%, 22.5 \%$ and $22.2 \%$ for suicidal ideation, suicidal plan and suicidal attempt respectively. Again, the current finding is inconsistent with the study of Quarshie, Osafo, Akotia and Peprah (2015) in which it was stated that there was an increase in adolescent suicide rates in Ghana. The current finding does not agree with the study of Li et al (2014) who indicated that the prevalence of suicidal ideation in Chinese college students was relatively high, although the suicide rate was lower compared with the entire society. One of the possible reasons for this current finding could be the fact that the concept suicidal ideation and suicide is relatively new in the Ghanaian environment so it is possible that adolescents might have not even heard much about suicide not to talk of contemplating one.

Hypothesis two was formulated to find out if there was a significant difference in suicidal tendencies of adolescents on the basis of gender. The study revealed that there was no significant difference in suicidal tendencies of adolescents on the basis of gender. The current findings does not agree with the finding of Quarshie, Osafo, Akotia and Peprah (2015) who indicated that compared to males, females were more likely to have suicidal ideation and suicidal plan. The current finding is also inconsistent with a study by Oppong (2015) on suidality in street children and adolescents in Ghana which showed a highly significant difference between the proportion of females reporting suicidal plans and attempts compared to their male counterparts.

The current finding may be attributed to the fact that the Ghanaian culture sees suicide to be alien and, therefore, adolescents do not see it as a way to terminate their lives. In addition, it is possible that adolescents have not yet encountered any life event which would put them in the state to have suicidal tendencies. This is because the respondents used for the study were relatively young.

\section{Conclusions}

Although adolescents risk behaviours have been prevalent among senior high school students in the Cape Coast Metropolis, the current study has indicated that the situation is not the same with respect to the junior high school students. This was evident as adolescents in the OLA circuit of the Cape Coast Metropolis indicated that they did not engage themselves in any of the risk behaviours the current investigated. The study has also provided vital information concerning the current engagement practices of the adolescents in the Cape Coast Metropolis in terms of risk behaviours. It can, therefore, be said that adolescents in the OLA circuit of the Cape Coast Metropolis do not engage in risk behaviours such as violence-related behaviour, alcoholism, smoking, risky sexual behaviours and suicidal tendencies. This study has exposed to stakeholders, the broad picture of the adolescents risk behaviours pertaining to junior high school students for the necessary actions to be taken.

\section{Recommendations}

On the basis of the findings, the following recommendations are made:

1. The Ministries of Health, Education, Youth and Sports, National population Council (NPC), among others should continue to intensify their campaigns against adolescents risk behaviours since it is 
impacting positively in the lives of adolescents.

2. Head teachers, teachers and parents must collaborate to intensify their supervisory roles both in school and after school. This will help foster in the adolescents some moral values and keep them from all forms of risk behaviours.

3. Since the majority of the respondents were religious, it will be important for the various religious leaders not to neglect but educate the adolescents in their congregation.

\section{Guidance Implications}

1. As the findings have shown from the current study that adolescents' engagement in risk behaviours are very minimal, guidance and counselling services should be extended and intensified at the basic level of education in Ghana by the Ghana Education Service.

2. From the findings of the study, it would be prudent for guidance coordinators, counsellors and teachers to continue exposing adolescents to risk behaviours irrespective of their age.

3. Since the study revealed that both male and female adolescents have the ability to engage in the risk behaviours, educators and counsellors in schools must not focus on one group alone.

\section{References}

Acquah, E. O., Wilson, M. L., \& Doku, D. T. (2014). Patterns and correlates for bullying among young adolescents in Ghana. Social Science, 3, 827-840.

Adinkrah, M. (2010). Epidemiologic characteristics of suicidal behaviour in contemporary Ghana. Crisis, 31, $32-$ 36.

Adu-Mireku, S. (2003). Prevalence of alcohol, cigarette, and marijuana use among Ghanaian senior secondary students in urban setting. Journal of Ethnicity in Substance Abuse, 2(1), 53-65.

Agyei, W. K. A. (2000). Sexual behaviour and contraception among unmarried adolescents and young adults in Greater Accra and Eastern Regions of Ghana. Journal of Biosocial Science, 32, 495-512.

Al-Yousaf, M. A., \& Karim, A. (2001). Prevalence of smoking among high school students. Saudi Medical Journal, $22(10), 872-874$

Amedahe, F. K. (2002). Fundamentals of educational research methods. Unpublished document for educational research methods, University of Cape Coast, Ghana.

Amonoo-Lartson, R., \& Pappoe, M. E. (1992). Prevalence of smoking in secondary schools in the Greater Accra region of Ghana. Social Science \& Medicine, 34(12), 91 -93.

Asante, K. O., Kugbey, N., Osafo, J., Quarshie, E. N. \& Sarfo, J. O. (2017). The prevalence and correlates of suicidal behaviours (ideation, planned and attempt) among adolescents in senior high schools in Ghana. SSMPopulation Health, 3, 427-434.

Awusabo-Asare, K., \& Biddlecom, A. (2006). Adolescent sexual and reproductive health in Ghana: Results from the 2004 national survey of adolescents (Occasional Report No. 22). New York, NY: The Alan Guttmacher Institute.

Boamah, E. A. (2012). Sexual behaviours and contraceptive use among adolescents in Kintampo, Ghana. Unpublished Master's thesis, Vrije Universitiet Amsterdam.

Colin, M. (2013). Cambridge advanced learner's dictionary (4 ${ }^{\text {th }}$ ed.). Cambridge, MA: Cambridge University Press.

Creswell, J. W. (2003). Qualitative, quantitative and mixed methods approaches (2 ${ }^{\text {nd }}$ ed.). London: Sage publication.

Doku, D. (2012). Substance use and risky sexual behaviours among sexually experienced Ghanaian youth. BMC Public Health, 12, 1-7.

Emeke, E. A., \& Adegoke, B. A. (2005). Prevalence of smoking behaviour among adolescents in Ibadan SouthEast Local Government, Nigeria. International Journal of Emotional Psychology and Sports Ethics, 7, 59-69.

Fatoye, F. O. (2003) Psychosocial correlates of substance use amongst secondary school students in south western Nigeria. East Africa Medical Journal, 80, 154-158.

Fawibe, A. E., \& Shittu, A. O. (2011). Prevalence and characteristics of cigarrete smokers among undergraduates of the University of Illorin, Nigeria. Nigeria Journal of Clinical Practice, 14(2), 201-205.

Fraenkel, J. R., \& Wallen, N. E. (2002). How to design and evaluate research in education (4th ed.). Boston: McGraw-Hill.

Ghana Statistics Service. (2008). Ghana demographic and health survey report. Ghana Health Service, Accra, Ghana.

Ghana Education Service. (2016). Statistics on schools in the Cape Coast Metropolis. Cape Coast, Ghana.

Hurrelmann, K., \& Richter, M. (2006). Risk behaviour in adolescence. The relationship between developmental and health problems. Journal of Public Health, 14, 20-28.

Jessor, R. (1998). New perspectives on adolescent risk behaviour. New York, NY: Cambridge University Press. 
Karim, A. M., Magnani, R. J., Morgan G. T., \& Bond, C. K. (2003). Reproductive health risk and protective factors among unmarried youth in Ghana. International Family Planning Perspectives, 29(1), 14-24.

Kokutse, F. (2012). Ghana youth suicide rate rises amidst taboos. Retrieved from http://www.rnw.nl/africa/article/ghanayouth-suicide-rate-rises-amidst-taboos

Krejcie, R. V., \& Morgan, D. W. (1970). Determining sample size for research activities. Educational and Psychological Measurement, 30, 607-610.

Kulbok, P.A., \& Cox, C. L. (2002). Dimensions of adolescent health behaviour. Journal of Adolescent Health, 31, $394-400$

Lamptey, J. J. (2005). Socio-Demographic characteristics of substance abuse admitted to a private specialist clinic. Ghana Medical Journal, 39, 1-7.

Li, Z., Li, Y., Lei, X., Zhang, D., Liu, L., Tang, S., \& Chen, L. (2014). Prevalence of suicidal ideation in Chinese College students: A meta-analysis. PLoS ONE, 9(10) 1-12.

National Population Council. (2000). Ghana adolescent reproductive health policy. Retrieved from http://www.youthpolicy.com/Policies/Ghana\%20Adolescent\%20Reproductive\%20Health\%20Policy.pdf

Nkyi, A. (2014). Substance abuse among senior high school students in Ghana. International Journal of Social Science and Education, 4(2), 346-353.

Nyarko, A. S. (2015). A sociological assessment of the causes and consequences of youth violence in the Kumasi Metropolis. Unpublished master's thesis, Kwame Nkrumah University of Science and Technology, Kumasi, Ghana.

Oppong, A. K. (2015). Exploring age and gender differences in health risk behaviours and psychological functioning among homeless children and adolescents. International Journal of Mental Health Promotion, 17(5), $278-292$.

Osafo, J., Hjelmeland, H., Akotia, C., \& Knizek, B. L. (2011). Social injury: An interpretative phenomenological analysis of the attitudes towards suicide of lay persons in Ghana. International Journal of Qualitative Studies, Health Well-Being, 6, 1-10.

Peltzer, K. P. (2009). Prevalence and correlates of substance use among school children in six African countries. International Journal of Psychology, 44(5), 378-386.

Quarshie, E. N. B., Osafo, J., Akotia, C. S., \& Peprah, J. (2015). Adolescent suicide in Ghana: A content analysis of media reports. International Journal of Qualitative Studies on Health and Well-being, 10(1) 1-13.

Richter, M. (2010). Risk behaviour in adolescence: Patterns, determinants and consequences. Retrieved from http://r.search.yahoo.com/_ylt=AwrBT8JPi8ZZrNQAlnNXNyoA; ylu=X3oDMTEyNmVydm9uBGNvbG8 DYmYxBHBv

World Health Organization. (2012). Public health action for the prevention of suicide: A framework. Geneva: World Health Organization. 